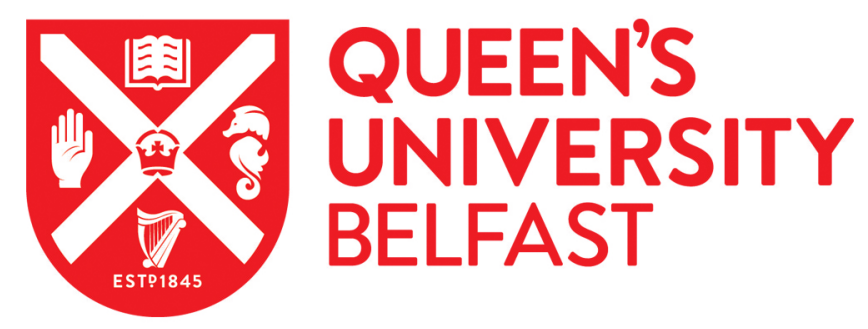

\title{
GROWTH KINETICS OF NUCLEI FORMED FROM DIFFERENT BINDERS AND POWDERS IN VERTICAL CYLINDRICAL MIXING DEVICES
}

\author{
Baghdadi, Y., Albadarin, A., \& Mangwandi, C. (2018). GROWTH KINETICS OF NUCLEI FORMED FROM \\ DIFFERENT BINDERS AND POWDERS IN VERTICAL CYLINDRICAL MIXING DEVICES. Chemical \\ Engineering Research and Design. https://doi.org/10.1016/j.cherd.2017.12.045
}

Published in:

Chemical Engineering Research and Design

\section{Document Version:}

Peer reviewed version

Queen's University Belfast - Research Portal:

Link to publication record in Queen's University Belfast Research Portal

\section{Publisher rights}

Copyright 2018 Elsevier.

This manuscript is distributed under a Creative Commons Attribution-NonCommercial-NoDerivs License

(https://creativecommons.org/licenses/by-nc-nd/4.0/), which permits distribution and reproduction for non-commercial purposes, provided the author and source are cited.

\section{General rights}

Copyright for the publications made accessible via the Queen's University Belfast Research Portal is retained by the author(s) and / or other copyright owners and it is a condition of accessing these publications that users recognise and abide by the legal requirements associated with these rights.

\section{Take down policy}

The Research Portal is Queen's institutional repository that provides access to Queen's research output. Every effort has been made to ensure that content in the Research Portal does not infringe any person's rights, or applicable UK laws. If you discover content in the

Research Portal that you believe breaches copyright or violates any law, please contact openaccess@qub.ac.uk. 


\title{
GROWTH KINETICS OF NUCLEI FORMED FROM DIFFERENT BINDERS AND POWDERS IN VERTICAL CYLINDRICAL MIXING DEVICES
}

\author{
Yasmine N. Baghdadi ${ }^{1,2}$, Rushab K. Shah ${ }^{1}$, Ahmad B. Albadarin ${ }^{1,3}$, Chirangano \\ Mangwandi ${ }^{1}$ \\ ${ }^{1}$ School of Chemistry and Chemical Engineering, Queen's University Belfast, Belfast BT9 5AG, \\ Northern Ireland, UK \\ ${ }^{2}$ Department of Chemical and Petroleum Engineering, American University of Beirut, Lebanon \\ ${ }^{3}$ School of Natural Sciences, Bernal Institute, University of Limerick, Limerick, Ireland
}

\begin{abstract}
Granulation is the process of forming large aggregates from fine particles using a high shear mixer. This method is used in several industries from pharmaceuticals to chemical and fertilizer production. This research will study the effect of four process variables: speed of mixer rotation in the range 100 to $200 \mathrm{rpm}$, powder bed mass ( 25 to $40 \mathrm{~g}$ ), mass of the initial nucleus ( 0.6 to $2 \mathrm{~g}$ ), and binder viscosity (water, carboxymethyl cellulose (CMC) solutions with concentrations in the range 0.5 to $20 \mathrm{~g} / \mathrm{L}$ ) on single nuclei growth kinetics in low mixing devices. The powders under study were: lactose, tea, sugar, starch, and limestone. The results show the initial size of nuclei, the initial mass of the powder bed and binder viscosity and speed of rotation all influence the rate of nuclei growth. Analysis of the stokes deformation number of the nuclei show that growth rate of the nuclei decreases as the deformation number increases whilst the percentage gain in mass of the nuclei increases with increasing deformation number. The binder viscosity was shown to have the biggest influence of the growth rate of the nuclei. Results show that difference in powder density also has an effect on the growth kinetics of nuclei. The initial position of nuclei was also shown to influence the nuclei growth rate; the closer the starting position of the nuclei to the wall of the vessel the slower the growth rate.
\end{abstract}

\section{KEYWORDS}

Granulation, Speed of rotation, Binder viscosity, Powder type, Growth kinetics

Corresponding author: E-mail: c.mangwandi@qub.ac.uk Tel: +44-(0)-28-90974378 


\section{INTRODUCTION}

Granulation is, by definition, the act of agglomerating particles together to form larger, semipermanent aggregates using a high shear mixer [1]. Some of the most important reasons for granulating powder-like material are eliminating dust handling hazards, increasing bulk density for storage, and creating non-segregating blends of different ingredients [2]. The process of granulation plays a major role in numerous industries such as fertilizers, pharmaceuticals, and fine chemicals. For instance, in the pharmaceutical industry, granulation is used to develop raw material with the required flow properties, compactness, and homogeneity[3].

There are two types of granulation processes. Wet granulation is the process of mixing a dry powder with a binder whereas dry granulation is the use of pressure (slugging or roller compaction) to form nuclei [4]. This project will tackle the process of wet granulation through the introduction of a wet binder into a rotating dry powder bed. This process can be divided into three stages of rate processes: wetting and nucleation, consolidation and growth, and breakage and attrition [5].

The first stage in the granulation process is wetting and nucleation; when the liquid binder is added to dry powder in order to form the nuclei of the granules. At this stage, a defining factor is the size of the binder droplet with respect to that of a unit particle. When the size of the droplet is larger than that of the particle, then a distribution of tiny granules called nuclei are formed. The binder is sprayed onto the powder bed where its drops coalesce and increase their effective size. By capillary action, the drops penetrate the powder bed and create wet clusters that break apart into granules of different sizes as a result of shear forces acting on the system. On the other hand, if the droplet size is less than the particle size, then the liquid is said to coat the particles [2].

The second stage is consolidation and growth in the granulation process. It is considered as the period during which the nuclei grow; either by collision of two nuclei, mixing of the granule with dry powder, or collision of nuclei with the equipment used. Under stable conditions of granule viscosity, plasticity, and malleability, compressive and shear forces push particles close together. During this process, the initial nuclei tend to gain weight and grow. This process is dependent on the energy of collisions [6]. The third, and final stage in the granulation process is attrition and breakage which refers to the period when the granules lose some of their gained weight due to their collision, with either the walls of the vessel or other granules [7].

Several parameters may affect the granulation process: (i) Binder introduction and content play a major role in granule growth kinetics; (ii) The way the binder is introduced changes the degree of wetting and the extent of spreading on the powder bed [8]; (iii) In addition to that, the type of binder viscosity induces consolidation and affects particle growth. The binder plays a role in defining the maximum pore saturation within the nucleus [9]. Also, the initial size of the particle plays a role in the yield strength of the granule; as the size decreases, the strength increases.

Finally, equipment speed and type is a major factor in nucleation growth kinetics. Mixer rotational speed has been the focus of many studies about granulation processes [1, 10-13]. It is a source of shear forces created within the studied system. This factor can lead to both growth and breakage of formed granules [14].

Since there are several variables affecting granulation, the purpose of this project was to develop a mathematical relationship that correlates the different variables of a wet granulation process to the growth rate of a single nucleus. In order to eliminate the effect of breakage, a low shear mixing system without an impeller was used. Powder mixing was achieved by the rotating the mixing vessel. In this research, several parameters were changed in order to find the optimal conditions that enable proper granulation. Different powder materials, namely lactose, tea, sugar, limestone, and starch were used 
as starting materials. The parameters that were investigated are rotational speed $(150 \mathrm{rpm}, 200 \mathrm{rpm}$, 250rpm, 300rpm, 400rpm), initial mass of powder bed $(25 \mathrm{~g}, 30 \mathrm{~g}, 35 \mathrm{~g}, 40 \mathrm{~g})$, initial mass of granule $(0.6 \mathrm{~g}, 0.8 \mathrm{~g}, 1.2 \mathrm{~g}, 1.6 \mathrm{~g}, 2 \mathrm{~g})$, and binder viscosity (water, $\mathrm{CMC}(0.5 \mathrm{~g} / \mathrm{L}), \mathrm{CMC}(1 \mathrm{~g} / \mathrm{L}), \mathrm{CMC}(2 \mathrm{~g} / \mathrm{L})$, CMC (10g/L), CMC (20g/L)).

\section{MODELLING}

Here, it is proposed that once a nucleus is formed it grows through a layering mechanism by capturing the primary powder particles from the moving powder bed. The rate of mass transfer between the nuclei and the bed is a function of the amount of binder available on the surface, the rolling action of the nuclei on the bed (influenced by the process conditions i.e. speed of rotation of the vessel or impeller). Assuming that the conditions in the mixer prevail such that there is no breakage of the nuclei, each nucleus will achieve a maximum size which is influenced by the availability of binder for layering.

The hypothesis is that the rate of nuclei growth decreases as the amount of binder available for nuclei growth is depleted. It is assumed to be proportional to the difference between the current nuclei size $\mathrm{M}(\mathrm{t})$ and the maximum achievable nuclei is $\mathrm{M}_{\max }$, hence one can write:

$$
-\frac{d M}{d t}=k\left(M_{\max }-M\right)
$$

Re-arranging Eq.(1) gives:

$$
\frac{d M}{\left(M_{\max }-M\right)}=-k d t
$$

Integrating LHS and RHS sides of equation (2) with respect to mass and time respectively gives:

$$
\ln \left(M_{\max }-M\right)=-k t+\text { const. }
$$

Applying the boundary condition when $\mathrm{t}=0, \mathrm{M}(\mathrm{t})=\mathrm{Mo}$ (initial mass of the nuclei), allows the value of the constant of integration to be determined:

$$
\text { const. }=\ln \left(M_{\max }-M_{0}\right)
$$

Hence;

$$
\ln \left(M_{\max }-M(t)\right)=-k t+\ln \left(M_{\max }-M_{0}\right)
$$

Re-arranging gives:

$$
\ln \left[\frac{M_{\max }-M(t)}{M_{\text {max }}-M_{0}}\right]=-k t
$$

The mass of a nucleus at any given time can be obtained from re-arranging Eq. 6 to make M(t) subject of the formula:

$$
M(t)=M_{\max }-\left(M_{\max }-M_{0}\right) e^{-k t}
$$


where $M_{\max }$ and $M_{0}$ are the maximum mass the nucleus can reach and the initial mass of the nucleus respectively; $k$ is the rate of nuclei growth in $\mathrm{s}^{-1}$ and $t$ is time is seconds. The parameter is introduced into the equation to take cognisance of the fact that the nuclei will not experience perpetual growth. The growth rate constant is influenced by material variables such as binder and powder properties and process variables.

\section{MATERIALS AND METHODS}

\subsection{Material and Equipment}

The $\alpha$-Lactose monohydrate, and starch were supplied by Sigma-Aldrich, UK. Limestone powder was supplied was a gift from Kilwaughter Chemicals Ltd. UK. Teawaste powder was collected from cafeteria at Queen's University Belfast. Carboxymethyl cellulose was sourced from Acros Organics US.

The particle densities of the material were determined using helium pyconometery (AccPyc II 1340 Pyconometer, Micromeritics USA) and results are reported in table 1. It can be note that particle densities of starch and lactose were similar whilst limestone had the highest particle densities. Teawaste was the lightest material. The particle size distribution was determined using Microtrac S3500 Particle Sizer Laser diffraction system. The surface-volume diameters $\left(\mathrm{d}_{3-2}\right)$ of the materials are summarised in Table 1. As can be seen from the Table 1 limestone, starch and lactose had similar average particle sizes.

In order to make the nuclei visible in the powder bed, they were coloured by adding methylene blue to the binder. The methylene blue that was used was produced by Alfa Aesar. In addition to that, the binder used in the experiments was Carboxymethyl cellulose with an average M.W. of 700000 produced by Acros Organics. All experiments were performed in a bespoke granulator comprising of a EUROSTAR 60 control mixer produced by IKA Works and a cylindrical glass mixing vessel with an internal diameter of $100 \mathrm{~mm}$. The schematic in Figure 1 shows the experimental set-up used in the experiments.

Table 1: Optimized powder to binder ratios

\begin{tabular}{|c|c|c|c|}
\hline Powder type & $\begin{array}{c}\text { True Particle } \\
\text { Density }\left(\mathrm{g} / \mathrm{cm}^{3}\right)\end{array}$ & $\begin{array}{c}\text { Ratio (powder to } \\
\text { binder) }\end{array}$ & $\mathrm{ds}, \mathrm{v}(\mu \mathrm{m})$ \\
\hline Lactose & $1.5552 \pm 0.0007$ & $1: 0.3$ & $13 \pm 3$ \\
\hline Tea & $1.4385 \pm 0.00078$ & $1: 1.5$ & $221 \pm 7$ \\
\hline Powdered Sugar & $1.6015 \pm 0.0002$ & $1: 0.1$ & $500 \pm 3$ \\
\hline Limestone & $2.7421 \pm 0.0004$ & $1: 0.22$ & $12 \pm 3$ \\
\hline Starch & $1.5054 \pm 0.0004$ & $1: 0.28$ & $12 \pm 1$ \\
\hline
\end{tabular}




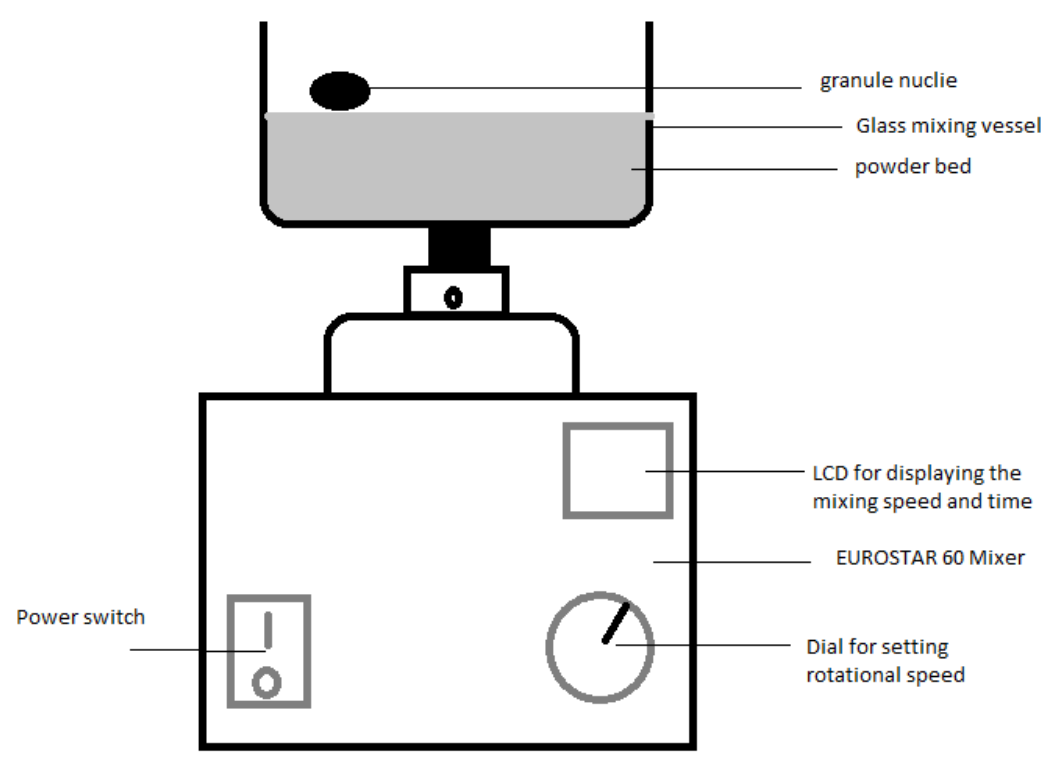

Figure 1: Schematic showing the experimental used in the experiments.

\subsection{Experimental Design}

A number of studies in literature have used response surface method as a tool for correlating the process and formulation variables to the product attributes $[11,12,16]$. A similar approach was used in this study to explore the correlation between the nuclei growth rate and as mentioned before, the effect of several variables on the growth kinetics of the granulation process will be studied. A custom user-defined design scheme was used to investigate the influence of speed of mixer rotation, amount of powder in the powder bed, initial nucleus size, and binder viscosity will be varied according to Table 2. This set of experiments was repeated for each type of powder under study. Therefore, the total number of experiments performed was 85 .

The nuclei growth rate was correlated to the process and formulation variables using equation of the form:

$$
y=\beta_{0}+\sum_{i=1}^{k} \beta_{i} \boldsymbol{x}_{i}+\sum_{1 \leq i<j}^{k} \boldsymbol{\beta}_{\boldsymbol{i} \boldsymbol{j}} \boldsymbol{x}_{\boldsymbol{i}} \boldsymbol{x}_{\boldsymbol{j}}+\sum_{i=1}^{k} \beta_{i j} x_{i}^{2}+\sum_{i=1}^{k} \beta_{i} x_{i}^{3}+\varepsilon
$$

where $\beta_{0}$ is the intercept term, $\beta_{i j}$ is the coefficient of the interaction terms, $\varepsilon$ is the residuals, $y$ is the response variable under investigation and $x$ is the dependent variable.

\subsection{Experimental Procedure}

Before beginning the experiments, water was added to a beaker and placed on a small magnetic stirrer. A bullet (mass $4 \mathrm{~g}, 35 \mathrm{~mm} \times 8 \mathrm{~mm} \times 8 \mathrm{~mm}$ ) was inserted into the solution and the shaker was turned on. CMC powder was added gradually to create $0.5 \mathrm{~g} / \mathrm{L}, 1 \mathrm{~g} / \mathrm{L}, 2 \mathrm{~g} / \mathrm{L}, 10 \mathrm{~g} / \mathrm{L}$, and $20 \mathrm{~g} / \mathrm{L}$ solutions respectively. The mixtures obtained were placed in jars and labelled. For the desired solutions of water and methylene blue, water was added to a beaker followed by methylene blue powder. The solution was then mixed until it became homogeneous. 
At first, two methods for granulation were used. In both cases, the first step was to weight the required amount of powder, place it in the vessel and spread it evenly before mounting the vessel onto the mixer. Next, to form the paste for the initial nucleus, different weight to weight ratios of binder to powder were used depending on the powder type. After several trials, the optimum ratios were summarized in Table 3.

Table 2: Experiments performed

\begin{tabular}{|c|c|c|c|c|c|}
\hline Experiment & Speed (rpm) & $\begin{array}{c}\text { Initial nucleus } \\
\text { mass (g) }\end{array}$ & $\begin{array}{c}\text { Initial powder } \\
\text { bed mass (g) }\end{array}$ & Binder & $\begin{array}{c}\text { Binder } \\
\text { Viscosity } \\
(\mathrm{mPa} . \mathrm{s})\end{array}$ \\
\hline 1 & 150 & 0.6 & 25 & Water & 1 \\
\hline 2 & 200 & 0.6 & 25 & Water & 1 \\
\hline 3 & 250 & 0.6 & 25 & Water & 1 \\
\hline 4 & 300 & 0.6 & 25 & Water & 1 \\
\hline 5 & 400 & 0.6 & 25 & Water & 1 \\
\hline 6 & 250 & 0.6 & 30 & Water & 1 \\
\hline 7 & 250 & 0.6 & 35 & Water & 1 \\
\hline 8 & 250 & 0.6 & 40 & Water & 1 \\
\hline 9 & 250 & 0.8 & 30 & Water & 1 \\
\hline 10 & 250 & 1.2 & 30 & Water & 1 \\
\hline 11 & 250 & 1.6 & 30 & Water & 1 \\
\hline 12 & 250 & 2 & 30 & Water & 1 \\
\hline 13 & 250 & 0.6 & 30 & CMC $(0.5 \mathrm{~g} / \mathrm{l})$ & 118 \\
\hline 14 & 250 & 0.6 & 30 & CMC $(1 \mathrm{~g} / \mathrm{l})$ & 285 \\
\hline 15 & 250 & 0.6 & 30 & CMC $(2 \mathrm{~g} / \mathrm{l})$ & 748 \\
\hline 16 & 250 & 0.6 & 30 & CMC $(10 \mathrm{~g} / \mathrm{l})$ & 5839 \\
\hline 17 & 250 & 0.6 & 30 & CMC $(20 \mathrm{~g} / \mathrm{l})$ & 12000 \\
\hline
\end{tabular}

Table 3: summary of optimum liquid to solid ratios for the formation of nuclei using different powders.

\begin{tabular}{|c|c|}
\hline Powder type & Ratio (powder to binder) \\
\hline Lactose & $1: 0.3$ \\
\hline Tea & $1: 1.5$ \\
\hline Powdered Sugar & $1: 0.1$ \\
\hline Limestone & $1: 0.22$ \\
\hline Starch & $1: 0.28$ \\
\hline
\end{tabular}


It is important to mention that in the case of sugar granulation, the sugar used to form the initial nucleus was powdered sugar. That is because it is very difficult to form a strong nucleus using granulated sugar. For the sugar bed, granulated sugar was used to perform the experiments. After the paste was formed, a nucleus was moulded such that its mass corresponded to the mass stated in Table 3. From this point on, two methods were used to complete the experiments. The first method was to form only one initial nucleus, placing it on the powder bed, setting the rotational speed in the mixer, and starting the mixer. For all experiment (with the exception with effect of initial position) the starting position of the nuclei was $20 \mathrm{~mm}$ from the centre of the cylinder. The nucleus can rotate in the mixer for 36 seconds considering that the mixer needs about 6 seconds to reach the set speed. After the mixer stopped, the new nucleus was gently taken out and weighed. Then, it was placed back on the powder bed at the same starting position and allowed to rotate again. The process was repeated 14 times. For each condition of experiment listed in Table 2, three replicate experiments were carried out. All results reported are based on the average of the replicates.

The second method was to form 9 initial nuclei and place them on the powder bed. One nucleus was extracted and weighed every 36 seconds. All the final nuclei were stored in plastic bags and labelled for further analysis. Figure 2 shows an example of the powder bed (lactose), the paste used to form the initial nucleus (lactose and water with methylene blue), and the initial nucleus.

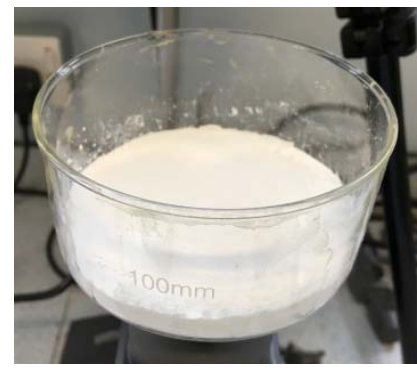

(a)

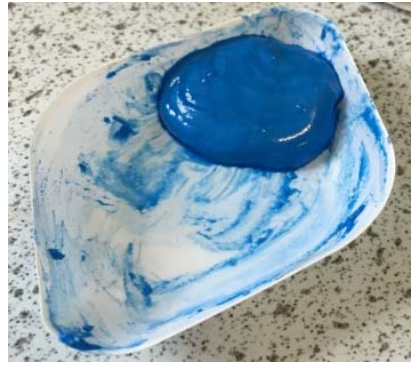

(b)

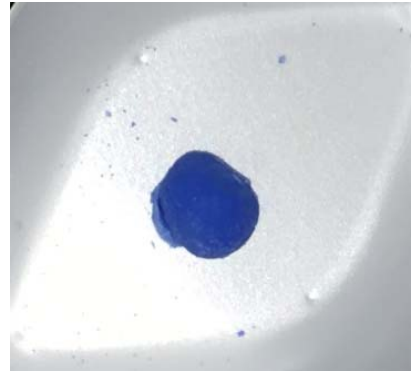

(c)

Figure 2: A lactose powder bed (a), lactose and water (with methylene blue) paste (b), and an initial lactose nucleus (c)

As will be explained later in the report, the position of the nucleus in the powder bed along with several other factors can play an important role in the granulation process. Using 9 different particles showed illogical variations in the growth kinetics. Therefore, only method one was considered for the analysis and discussion section of the report.

\subsection{Data Fitting}

After all the experiments were performed and the raw data was gathered, the variation in the mass of the granules for each experiment was plotted against time. This data was fitted using a MATLAB code and the rate of nucleus growth and its maximum attainable mass was calculated for further analysis using Eq. (8). 


\section{RESULTS AND DISCUSSION}

\subsection{Effect of speed of rotation on growth kinetics}

The first set of experiments was designed to test the effect of the variation in the mixer's speed of rotation on the granulation process. The speed was varied from $150 \mathrm{rpm}, 200 \mathrm{rpm}, 250 \mathrm{rpm}, 300 \mathrm{rpm}$, and 400rpm. The set was performed on all five powder types and the results seem to differ among them.

To be able to project the obtained results onto vessels of different diameters, the Froude number will substitute the speed of rotation in the preceding analysis as per the equation below:

$$
F r=\frac{2 \pi^{2} R_{v e s} N^{2}}{3600 g}
$$

Where, $\mathrm{R}_{\text {ves }}$ is the vessel radius $(\mathrm{m})$ and $\mathrm{N}$ is rotational speed of the vessel in revolution per minute (rpm) and $\mathrm{g}$ is acceleration due to gravity.

Figure 3 shows the variation of the rate of nuclei growth with respect to the Froude number which will be used instead of speed of rotation for all five powder types.

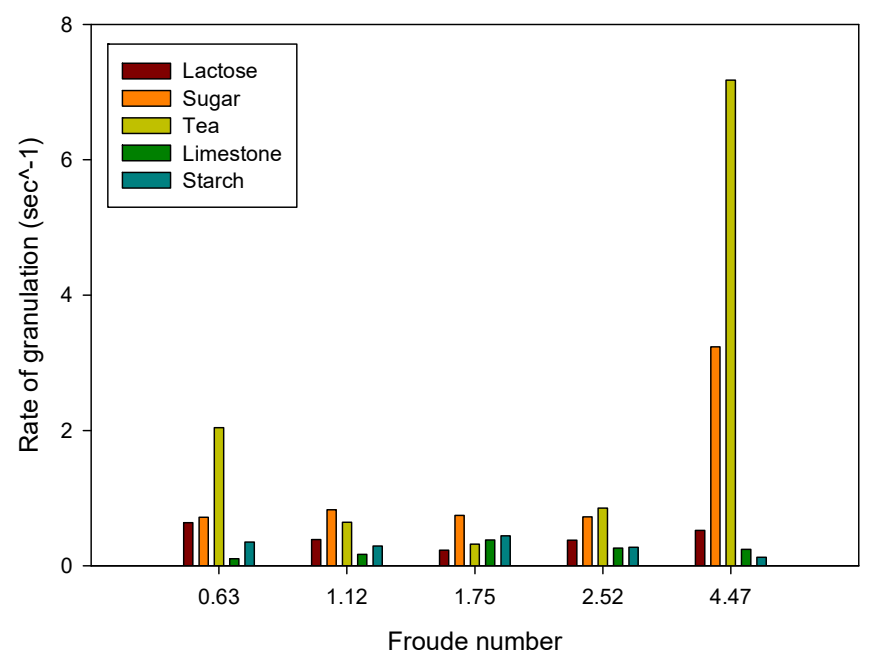

Figure 3: Variation in rate of nuclei growth with rotational speed for five powders

Considering that the vessel diameter is $100 \mathrm{~mm}$, the corresponding Fr numbers for the studied speeds are shown in Figure 3. For this set of experiments, the initial nucleus mass was $0.6 \mathrm{~g}$ placed in a $25 \mathrm{~g}$ powder bed and granulated using water with methylene blue.

For Lactose granulation, the highest rate of nuclei growth was at $\mathrm{Fr}=0.63$ and the lowest was at $\mathrm{Fr}=1.75$. Observations show that when the mixer was set at low speeds, the nucleus was not moving in the powder bed. In the case of lactose, movement of the nucleus started at $\mathrm{Fr}=1.75$. At low speeds, $(\mathrm{Fr}=0.63$ and $\mathrm{Fr}=1.12$ ), the centrifugal force for a nucleus of $0.6 \mathrm{~g}$ was calculated to be less than $26.31 \mathrm{mN}$. Accordingly, it was observed that this small force was not enough to make the nucleus move on the powder bed which in turn results in migration of the liquid binder from the centre of the nucleus to the surface of the nuclei. Upon reaching the surface of the nuclei the binder becomes available for interaction with fresh powder particles in the powder bed. Therefore, any increase in mass was due to the adhesion of lactose particles from the bed to the bottom of the stationary nucleus. 
Disregarding the first two data points $(\mathrm{Fr}=0.63$ and $\mathrm{Fr}=1.12)$, the remaining results show that as the speed of rotation increases from $\mathrm{Fr}=1.75$ to $\mathrm{Fr}=4.47$, the rate of nuclei growth almost doubles from $0.23 \mathrm{~s}^{-1}$ to $0.52 \mathrm{~s}^{-1}$ which can be attributed to increase in the collision frequency when rotational speed of the vessel is increased.

Similar results are shown in the case of tea granulation, the rate of nuclei growth increased from $0.32 \mathrm{~s}^{-1}$ at $\mathrm{Fr}=1.75$ to $1.18 \mathrm{~s}^{-1}$. Although the trend is similar, it is apparent that the rate of nuclei growth at $\mathrm{Fr}=4.47$ is almost 13 times greater in the case of tea. The high growth rate of tea nuclei at both high and low Fr numbers may be attributed to higher binder content of the tea nuclei (see Table 2) compared to nuclei from other materials. Higher binder content would promote the capturing of more tea powder primary particles hence the observed high growth rate. If the availability of the binder was the only contributing factor towards the nuclei growth rate, one would expect lactose and starch to exhibit the same growth rate since they have similar liquid to solid ratios. However this was not the case lactose exhibited a growth rate which was almost 5 time higher than that of starch. This suggest that other factors such as interaction between the powder and binder, powder particle size could also be important factors influencing the growth rate. For instance solubility of the powder primary particle in the binder (water in this case) could also influence the bonding mechanism. Solubilisation of powder particle and subsequent formation of crystallisation bonds could in some sense promoted nuclei growth in the case of powders which are readily soluble in the binder (sugar, lactose)

Also, in the case of sugar granulation, the rate was highest at $F r=4.47\left(3.24 \mathrm{~s}^{-1}\right)$. When put all together, it can be concluded that for tea, lactose, and sugar nuclei growth is faster at higher speeds of mixer rotation. Tea granulates the fastest followed by sugar then finally by lactose.

Figure 4 shows a lactose nucleus after its mixing at $\mathrm{Fr}=0.63$. It is evident from this figure that the nuclei is smooth and almost spherical suggesting that the growth mechanism could be growth by laying and consolidation.

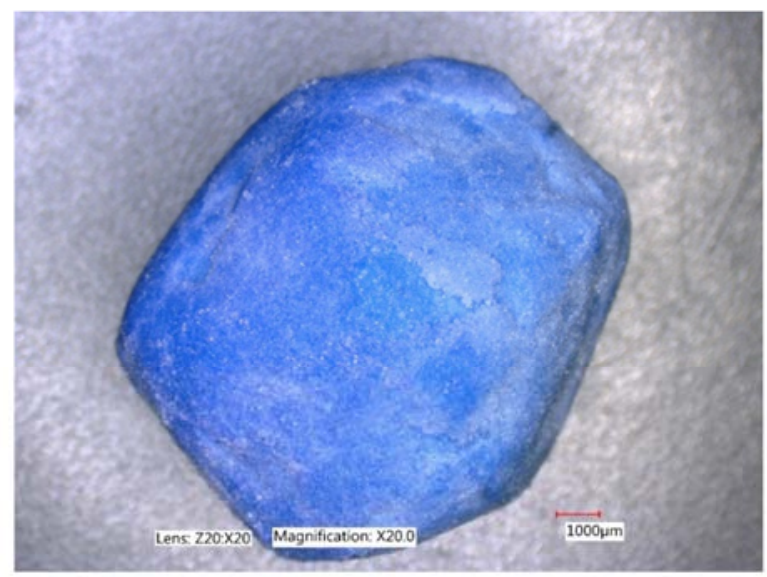

(a)

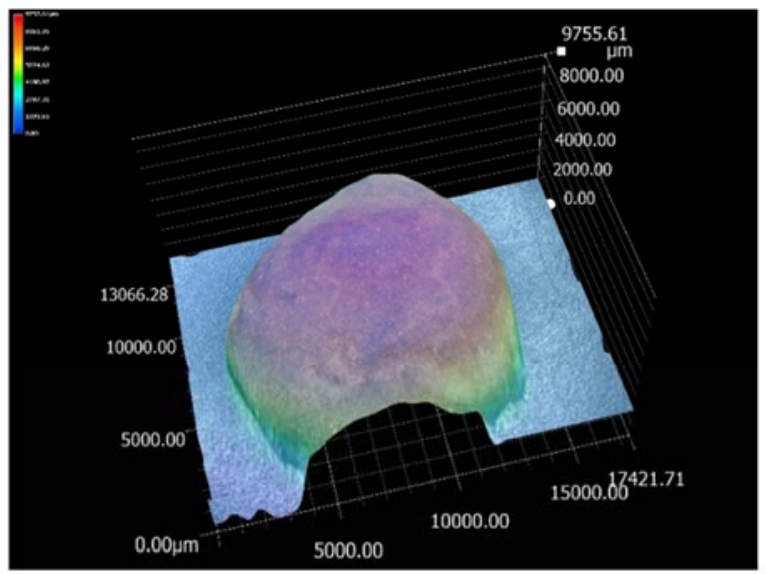

(b)

Figure 4: A magnification of the nucleus and spatial scan of the nucleus

Figure 5 shows the difference between the maximum attainable mass of the nucleus and the initial mass of $0.6 \mathrm{~g}$ for each powder type in a $25 \mathrm{~g}$ powder bed granulated with water and methylene blue: 


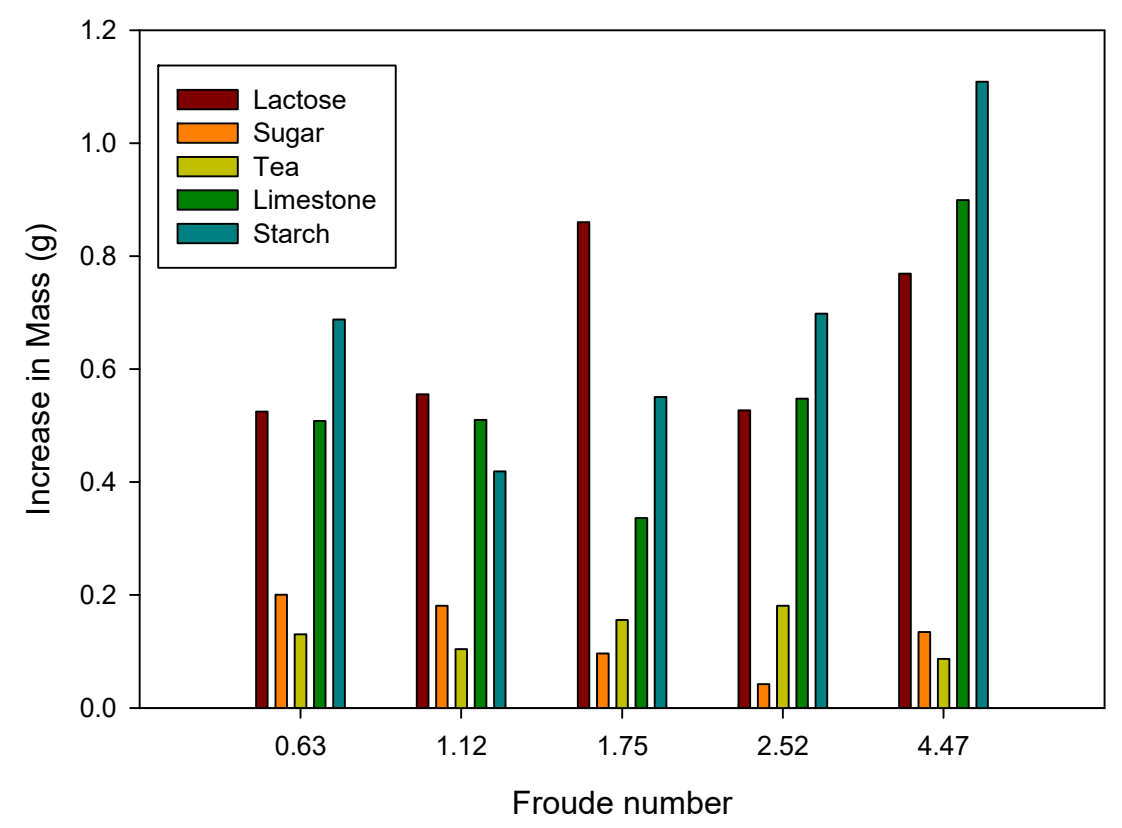

Figure 5: Variation of the increase in mass with rotational speed for five powders. All experimental data points were an average of 3 repetitions.

When it comes to studying the maximum attainable mass of a nucleus, the results show that the different powder types not only reach different maxima but also reach their maximum at different rotational speeds. Figure 6 shows the variation of nuclei mass with respect to time at all the monitored speeds of rotation for lactose as a sample.

Lactose was the only powder to reach a maximum of $1.46 \mathrm{~g}$ at $\mathrm{Fr}=1.75$. Tea reached a lower maximum of $0.78 \mathrm{~g}$ at $\mathrm{Fr}=2.52$. Starch $(1.70 \mathrm{~g})$, limestone $(1.50 \mathrm{~g})$ and sugar $(0.73 \mathrm{~g})$ all reached a maximum at $\mathrm{Fr}=4.47$. A careful observation of the obtained results shows that for materials of high density (lactose, limestone, and starch), the increase in mass is higher than materials of lower density (sugar, tea). That is, the density of the powder might be the reason for the large variation in the final mass.

To further validate this hypothesis, research conducted by Zhang et al. showed that low density materials rotating in a cylindrical vessel are more prone to move towards the edges of the vessel [17]. The research examined the effect of particle density on its mobility within the vessel. Therefore, it is hypothesized that, since tea and sugar have a low density with respect to the other powders, their movement in the powder bed was easier. This, in turn, made it difficult for the nuclei to attain good coverage when rotating in the bed and resulted in a lower increase in mass. 


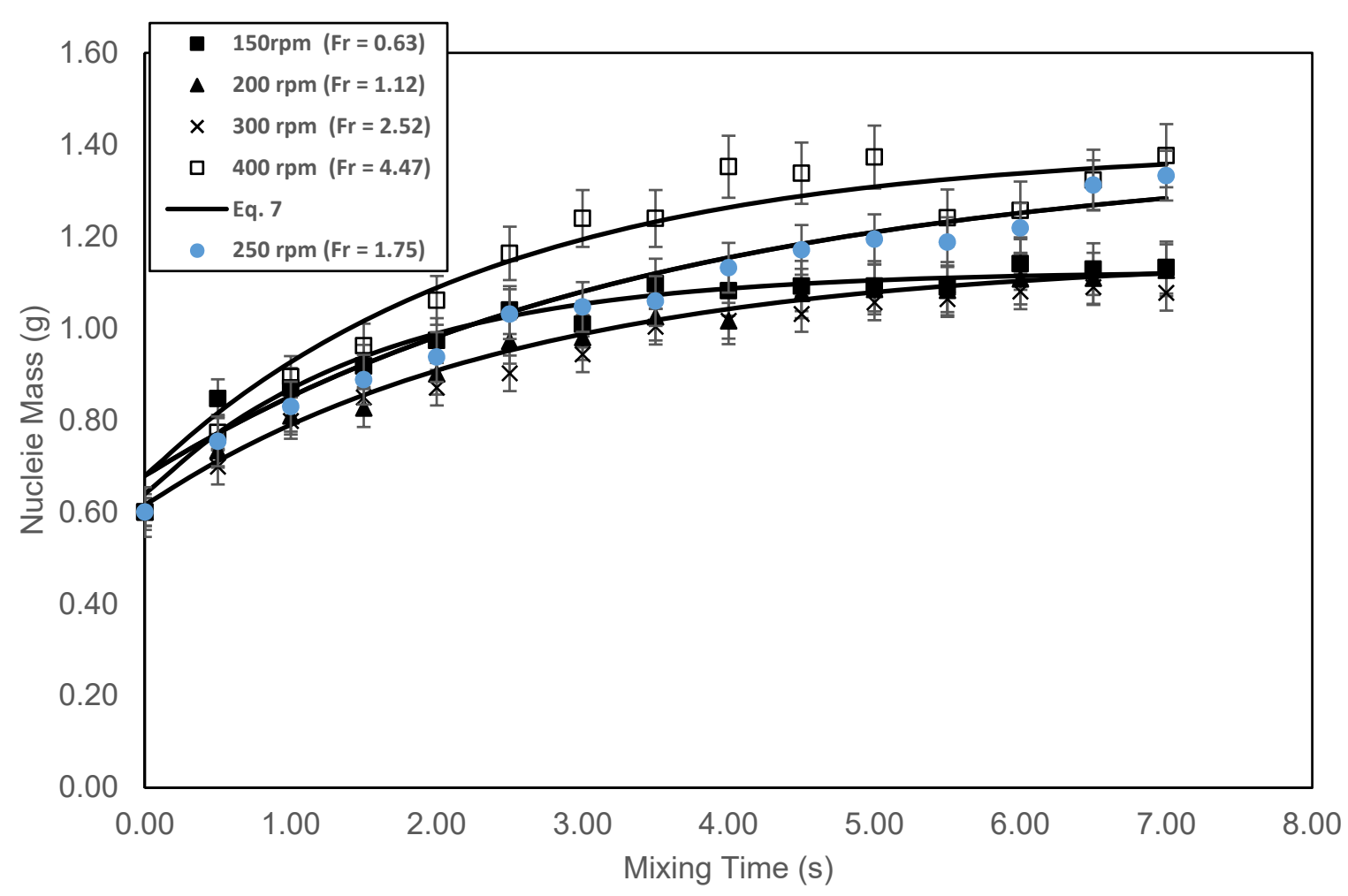

Figure 6: Data fitting showing the variation of nuclei masses with time at different values of Froude number for lactose. Please note that the continuous lines in the plot are plots of Eq. (7). All experimental data points were an average of 3 repetitions.

The difference in optimum speed can be attributed to several things. The degree of wetting of the initial nucleus, the voids within the nucleus, and the ability of the binder to move to the surface of the nucleus all play a role in the growth of the nuclei. To further validate the obtained results, a thorough scan of the obtained granules shows their cross-sectional areas. Figure 7 exemplifies a cross sectional area of a granule obtained at the set experimental conditions at a speed of rotation equivalent to 150 $\operatorname{rpm}(\mathrm{Fr}=0.63)$.

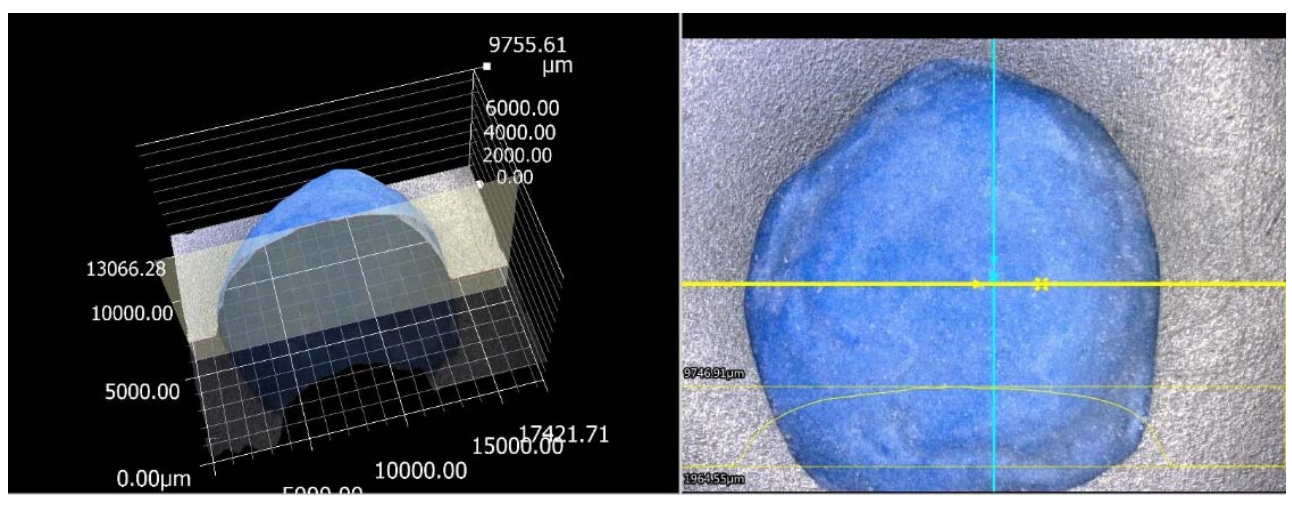

Figure 7: Spatial scan of a granule produced at $\mathrm{Fr}=0.63$

To better study the effect of the rotation speed on the granule's size and shape, the granule profiles are plotted and compared at different speeds. Figure 8 shows the results. 


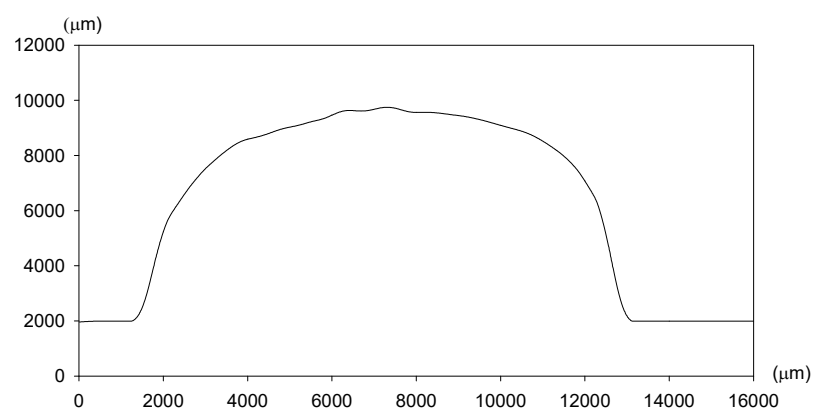

(a)

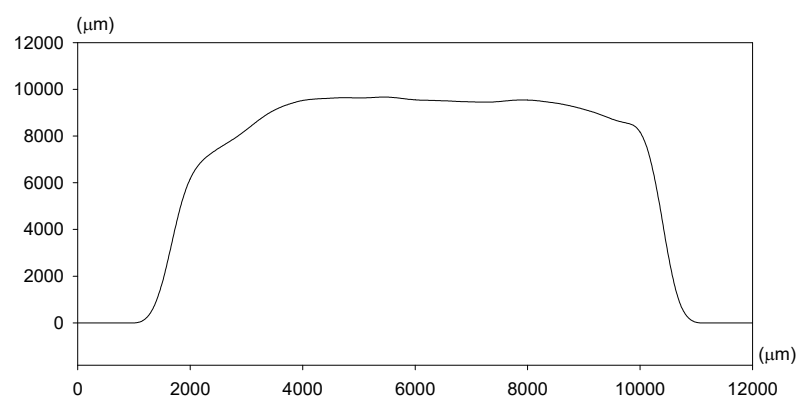

(c)

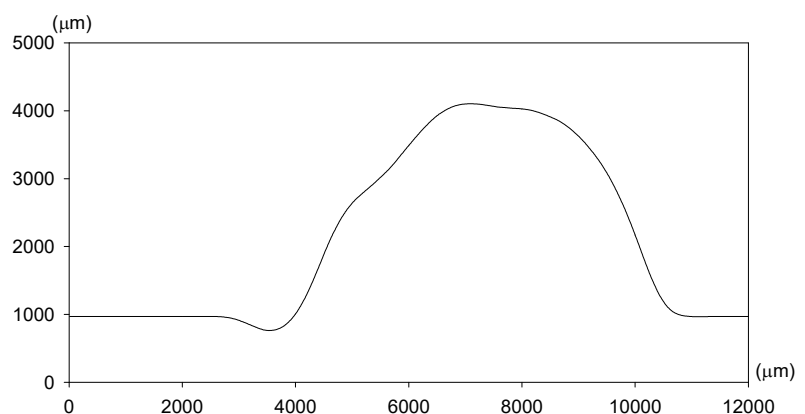

(b)

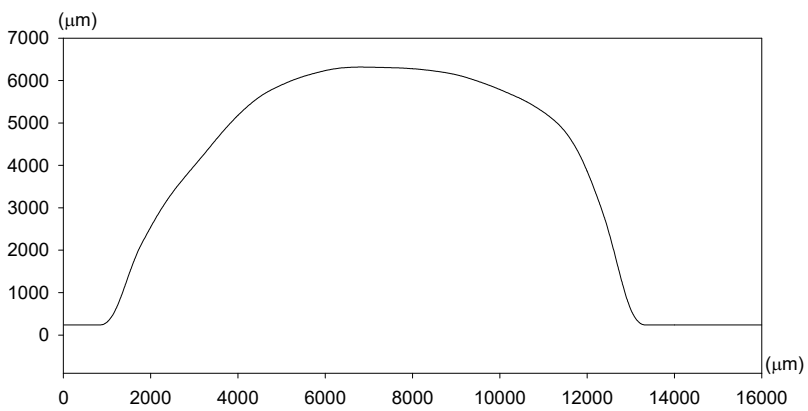

(d)

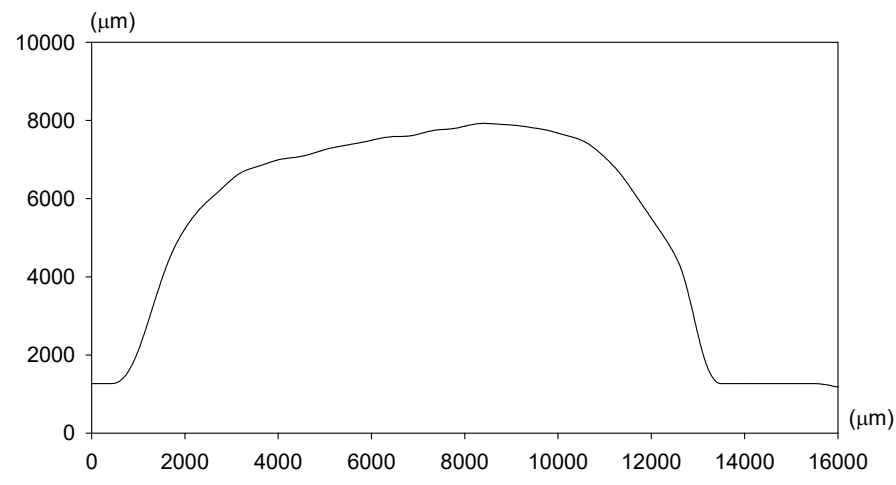

(e)

Figure 8: Granule profiles at $\mathrm{Fr}=0.63$ (a), $\mathrm{Fr}=1.12$ (b), $\mathrm{Fr}=1.75$ (c), $\mathrm{Fr}=2.52$ (d), and $\mathrm{Fr}=4.47$ (e)

The profiles depicted in Figure 8 are an effective way to monitor the effect of rotational speed on the surface roughness of the granule. Surface roughness, by definition, is a measurement that identifies the surface's "texture". Observing the figures, it is possible to qualitatively deduce that regardless of the mixer's rotational speed, the granule's surface is smooth. This is because there are no significant fluctuations present on the profile. The difference in the maximum height of the peaks is related to the differences in the sizes of nuclei which were randomly selected for the observation.

\subsection{Effect of the initial mass of the powder bed on growth kinetics}

The second set of experiments was designed to test the effect of the variation in the powder bed mass on the granulation process. The mass was varied from $25 \mathrm{~g}, 30 \mathrm{~g}, 35 \mathrm{~g}$, and $40 \mathrm{~g}$. The set was 
performed on all five powder types at $\mathrm{Fr}=1.75$ with an initial nucleus mass of $0.6 \mathrm{~g}$ using water and methylene blue. Typical results for growth curves for the starch powder are shown in Figure 9.

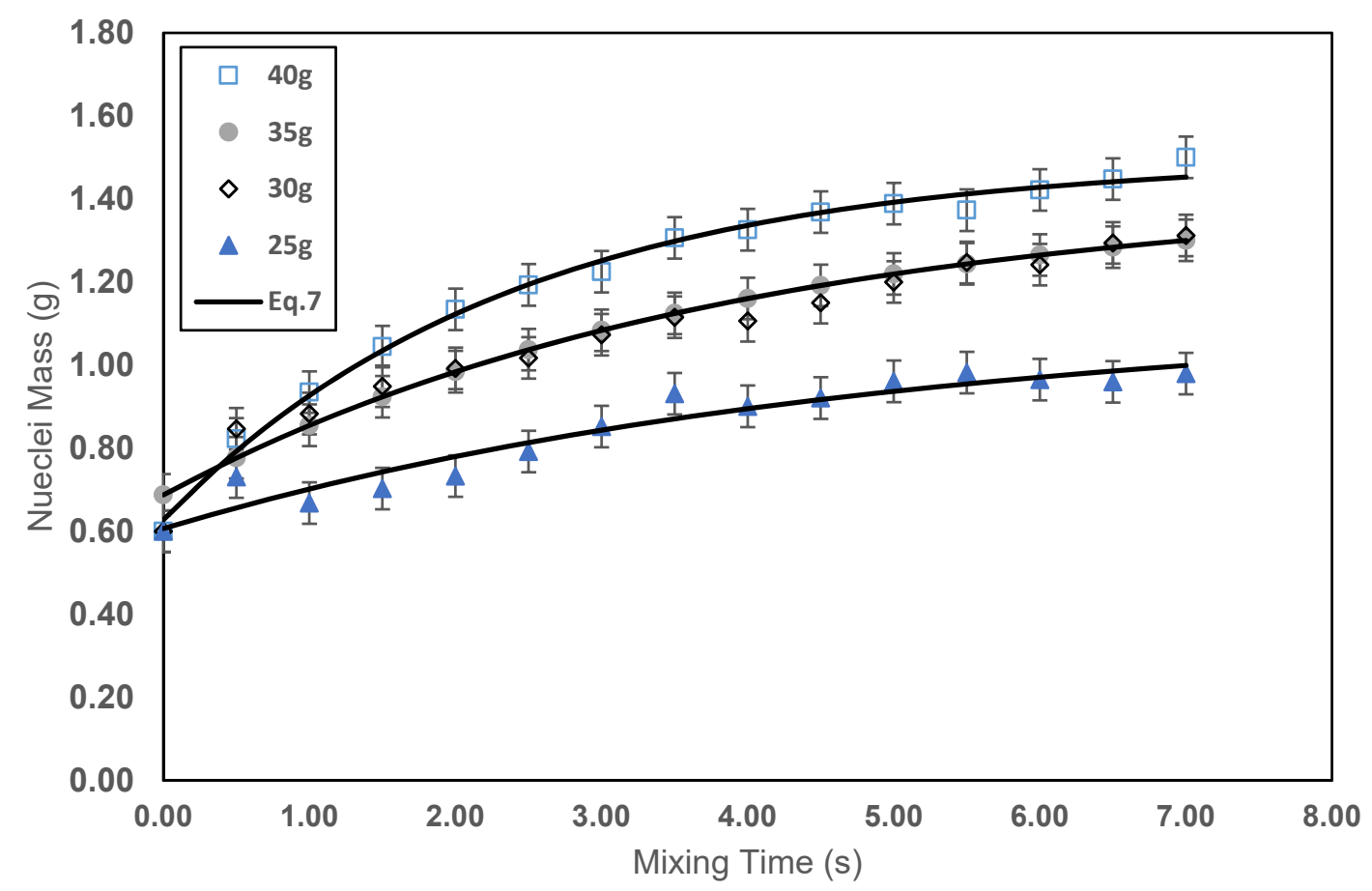

Figure 9: Variation of nucleus mass with time at different powder bed masses for starch. Please note that the continuous lines in the plot are plots of Eq. (7). All experimental data points were an average of 3 repetitions.

As regards the effect of powder bed mass on the rate of nuclei growth, experimental results show a difference between powder types. For lactose, sugar, and tea a similar trend is observed whereby rate of nuclei growth increases with the increase in the amount of powder in the container. The highest rate was achieved by sugar at $1.92 \mathrm{~s}^{-1}$ followed by tea at $0.79 \mathrm{~s}^{-1}$ and lactose at $0.42 \mathrm{~s}^{-1}$ at $40 \mathrm{~g}$. In the case of limestone granulation, the optimum rate of nuclei growth was $0.49 \mathrm{~s}^{-1}$ when the mass of the powder bed was $35 \mathrm{~g}$. As for starch granulation, the decrease in the amount of powder in the vessel seems to aid nuclei growth; the optimum rate of nuclei growth was $0.44 \mathrm{~s}^{-1}$ at $25 \mathrm{~g}$ of powder in the bed. The findings are summarized in Figure 10. 


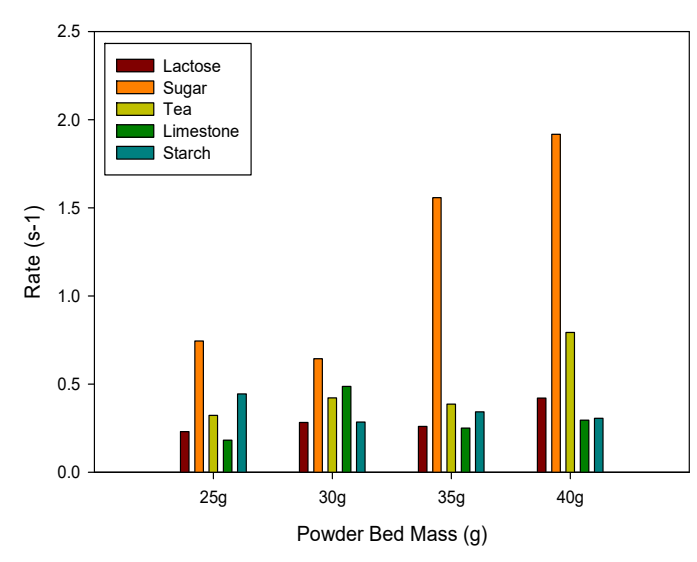

(a)

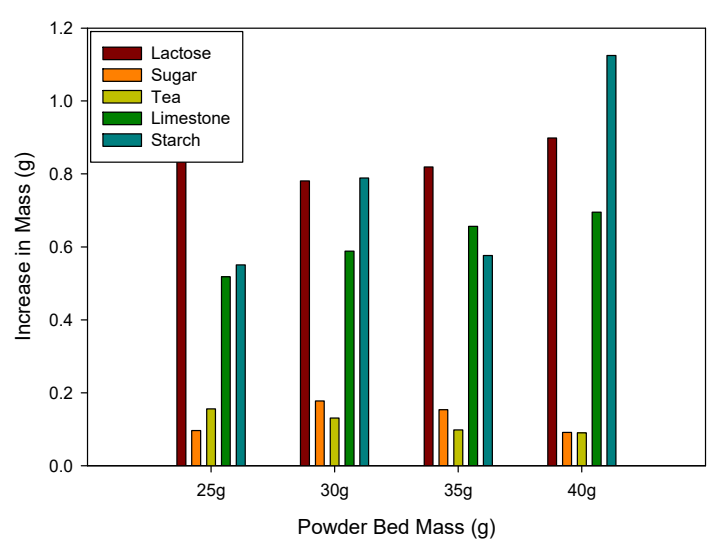

(b)

Figure 10: Variation of rate of nuclei growth (a) and mass gain (b) with powder bed mass for five powders

Figure 10 shows that, for sugar and tea, the change in powder bed mass did not affect nuclei growth as much. However, for lactose, limestone and starch, as the amount of powder initially present increased, the maximum attainable nucleus mass increased as well. The powder that is affected most is starch with the greatest increase in mass at $40 \mathrm{~g}$ of powder in the bed.

As previously mentioned, the lower the density of the powder density the more the separation in the powdered bed and the less the ability of the nuclei to granulate homogeneously. Therefore, an explanation for these results may be the difference in density between the powders. Lactose, limestone, and starch have approximately the same density and were observed to follow similar trends with high mass increase. On the other hand, for tea and sugar, which have low densities, the effect of powder bed mass does not seem to be evident.

\subsection{Effect of the initial mass of the nucleus on growth kinetics}

For this experimental set, the only variable was the initial mass of the nucleus. The speed of rotation was held constant at $\mathrm{Fr}=1.75$, the powder bed mass was $30 \mathrm{~g}$, and the binder used was water with methylene blue as the dye. Figure 11 shows the variation of mass with time for limestone as a sample of powder type. 


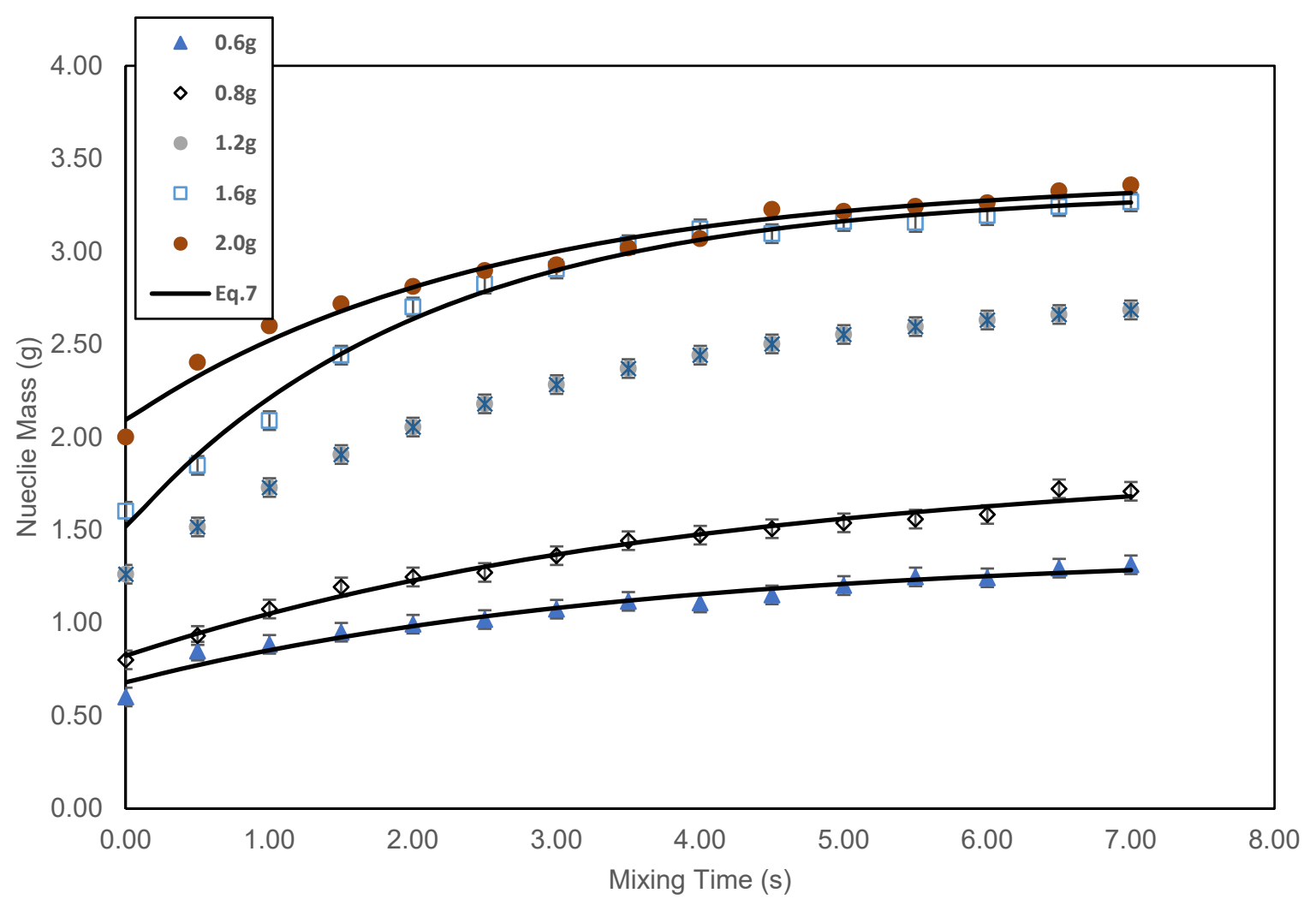

Figure 11: Variation of mass with time at different initial nucleus mass for limestone. Please note that the continuous lines in the plot are plots of Eq. (7). Experimental data points were an average of 3 repetitions.

The growth kinetics parameters obtained for fitting Eq. 7 to the experimental data is summarised in Figure 12.

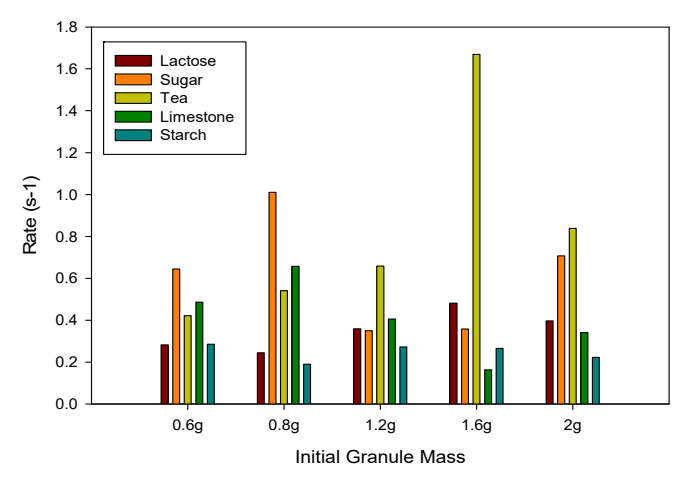

(a)

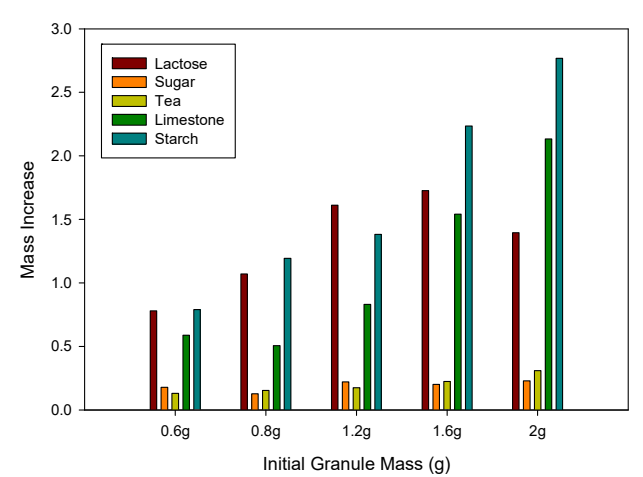

(b)

Figure 12: Variation of rate of nuclei growth (a) and mass gain (b) with initial mass of the nucleus for five powders. Rate of nuclei growth was obtained from fitting Eq. (7) to experimental data.

The results do not show a specific trend in relation to the initial mass of the nucleus. The different powder types granulated at different rates. The maximum rate of nuclei growth for sugar $\left(1.01 \mathrm{~s}^{-1}\right)$ and limestone $\left(0.66 \mathrm{~s}^{-1}\right)$ was when the initial nucleus was $0.8 \mathrm{~g}$. For lactose $\left(0.48 \mathrm{~s}^{-1}\right)$ and tea $\left(1.67 \mathrm{~s}^{-1}\right)$, the maximum rate of nuclei growth was attained when the initial nucleus was $1.6 \mathrm{~g}$. Out of the five studied 
powders, starch was the slowest to granulate; maximum granulation $\left(0.29 \mathrm{~s}^{-1}\right)$ was observed at the lowest initial nucleus size of $0.6 \mathrm{~g}$. The results for limestone and starch show a trend whereby the increase in initial nucleus mass resulted in a greater increase in final mass. For lactose, it was observed that nuclei growth peeked when the initial nucleus was $1.6 \mathrm{~g}$ but a further increase in initial mass had a negative effect on the process. The increase in nucleus mass with respect to initial mass was not as significant for sugar and tea.

\subsection{Effect of the binder viscosity on growth kinetics}

For this set of experiments, the speed of rotation was held at 250 $\mathrm{rpm}(\mathrm{Fr}=1.75)$, the initial nucleus mass was $0.6 \mathrm{~g}$, and the powder bed mass was $30 \mathrm{~g}$. The variable in this section was the binder's viscosity. In previous experiments, water with a viscosity of $1 \mathrm{mPa}$.s was used as a binder. In this set, $\mathrm{CMC}$ was used at different concentrations to study the effect of binder viscosity on granulation. It is important to note that in some of the experiments performed, the initial thrust when the mixer was turned on caused the nucleus to move to the edge of the vessel and stick to the wall. This phenomenon prevented homogeneous granulation. The results shown in Figure 13 indicate that for low density powders, the rate of nuclei growth was highest at a high viscosity. When CMC concentration was $10 \mathrm{~g} / \mathrm{l}$, the rate of tea and sugar granulation was at a maximum.

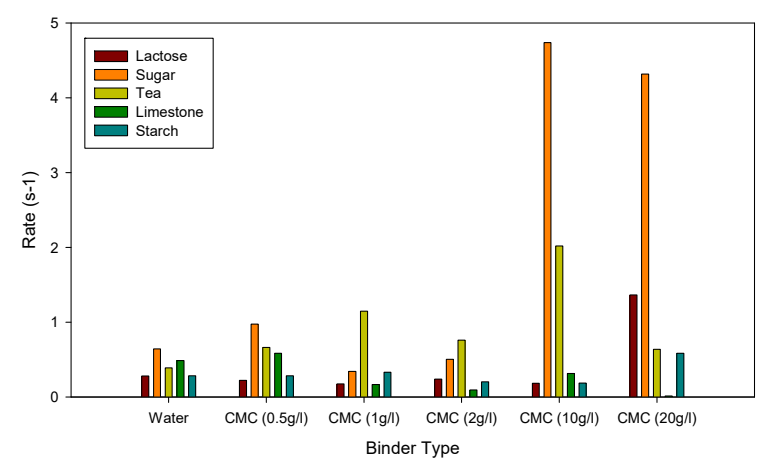

(a)

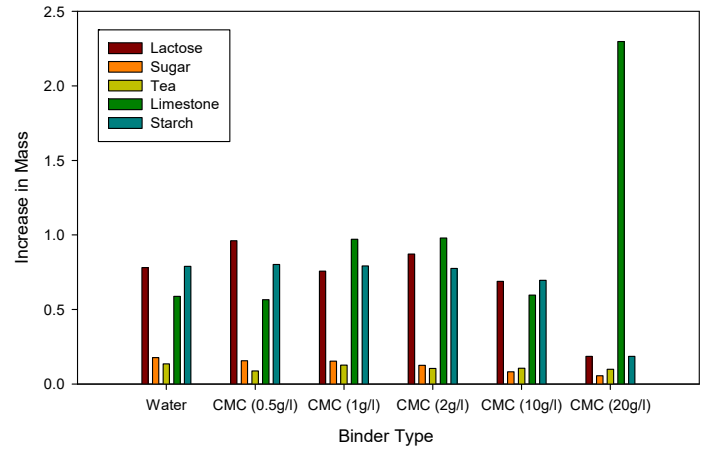

(b)

Figure 13: (a) Variation of rate of nuclei growth with binder type for five powders (b) effect of binder type on mass gain of the nucleus. Rate of nuclei growth was obtained from fitting Eq. (7) to experimental data.

Figure 13 (b) shows the effect of binder viscosity on the increase in mass of the nucleus. Starting off with the low-density powders, tea and sugar, the results show that the change in mass was insignificant. The maximum increase in mass for sugar was $0.18 \mathrm{~g}$ when using water as the binder. However, the value of mass increase when using $\mathrm{CMC}$ was not much different. The increase ranged from $0.08 \mathrm{~g}$ to $0.18 \mathrm{~g}$ only. For tea, the range of mass increase was $0.1 \mathrm{~g}$ to $0.13 \mathrm{~g}$ which is considered as insignificant. When studying the effect of binder viscosity on the growth for powders of higher density, it was observed that change in nucleus mass was higher at low concentrations of CMC. For starch and lactose, the maximum mass increase was $0.8 \mathrm{~g}$ and $0.96 \mathrm{~g}$ respectively when only $0.5 \mathrm{~g} / \mathrm{L}$ of $\mathrm{CMC}$ was used. That is, as the binder viscosity increases, the granulation efficiency decreases. For limestone, on the other hand, maximum mass increase was $2.30 \mathrm{~g}$ when the binder was $20 \mathrm{~g} / \mathrm{L} \mathrm{CMC}$.

Numerous research papers use granulation maps to relate nucleus properties to process variables $[18,19]$. These papers have managed to distinguish between two nucleus growth regimes: steady and induction growth $[20,21]$. A steady growth regime involves nuclei that are weak and deformable in a system with low viscosity binder liquids whereas induction growth involves strong and nondeformable granules in a highly viscous binder [20]. 
The use of low viscosity binders leads to the deformation of granules during particle collisions and squeezes the liquid to the surface of the granule. This aids granulation and is a valid explanation for the results shown in the Figure 13 (b) where mass increase was highest at low viscosity CMC solutions for starch and lactose. At high viscosity, more time was needed for the binder to seep to the surface of the nucleus which in turn leads to less granulation [22].

\subsection{Correlations and optimum solutions}

The results were analysed to determine the correlations that relate the four studied variables. Design-Expert Software was used to find the best fit for the experimental data gathered for each powder type. The software sowed that linear and quadratic relations with normalized values for better analysis. Tables 4 and 5 summarize the coefficients for the coded variables included in the correlations for the rate of nuclei growth as well as the maximum attainable mass of the nucleus.

Table 4: Coefficients for the variables for nuclei growth rate correlations using the coded variables

\begin{tabular}{|c|c|c|c|c|c|}
\hline Source term & Lactose & Sugar & Tea & Limestone & Starch \\
\hline Intercept & 0.35 & 4.81 & 3.09 & 0.13 & 0.16 \\
\hline $\mathrm{A}$ & -0.03 & 1.13 & 2.47 & 0.06 & -0.13 \\
\hline $\mathrm{B}$ & 0.06 & 0.74 & 0.25 & -0.43 & 0.09 \\
\hline $\mathrm{C}$ & 0.09 & 0.01 & 0.29 & -0.60 & 0.11 \\
\hline $\mathrm{D}$ & 0.56 & 1.83 & 0.05 & 1.89 & 0.25 \\
\hline $\mathrm{A}^{2}$ & 0.31 & 1.25 & 4.08 & -0.11 & -0.14 \\
\hline $\mathrm{B}^{2}$ & 0.08 & 0.55 & -0.09 & -0.11 & 0.03 \\
\hline $\mathrm{C}^{2}$ & -0.06 & 0.14 & -0.32 & 0.08 & 0.00 \\
\hline $\mathrm{D}^{2}$ & 0.59 & -2.04 & -1.49 & -0.17 & 0.24 \\
\hline $\mathrm{A}^{3}$ & & & & 0.01 & 0.02 \\
\hline $\mathrm{B}^{3}$ & & & & 0.45 & -0.13 \\
\hline $\mathrm{C}^{3}$ & & & 0.98 & 0.87 & -0.15 \\
\hline $\mathrm{D}^{3}$ & & & & -2.09 & -0.10 \\
\hline $\mathrm{R}-\mathrm{squared}_{\text {value }}$ & 0.97 & & & & 0.86 \\
\hline
\end{tabular}

Note that, A represents the speed of rotation, B represents the mass of the powder bed, C is the mass of the initial nucleus, and $\mathrm{D}$ is the binder viscosity and in all cases normalised values were used i.e. each variable was normalized to give values ranging from -1 to +1 , where -1 and +1 corresponds to the minimum and maximum values of the variable used in the experiment.

Table 3 summarizes the coefficients for the four studied variables in a nuclei growth rate equation for each type of powder. A quadratic equation defines the rate equations for lactose, sugar, and tea. A quartic equation gave a better fit for limestone and starch. 
The results show that the variable that affects the rate of nuclei growth most was binder viscosity. The highest coefficient for all powders, except tea, was for binder viscosity. The second variable was speed of rotation raised to the power two. The only case where initial nucleus mass was important was in the case of limestone but, when compared to the effect of binder viscosity, it can be considered as an insignificant factor. Typical surface plots (shown for sugar and lactose only) generated for equation (1) with the coefficients provided in Table 3 is shown in Figure 14. It can be seen from Figure 14 that binder viscosity has the strongest influence on the growth rate of the nuclei.
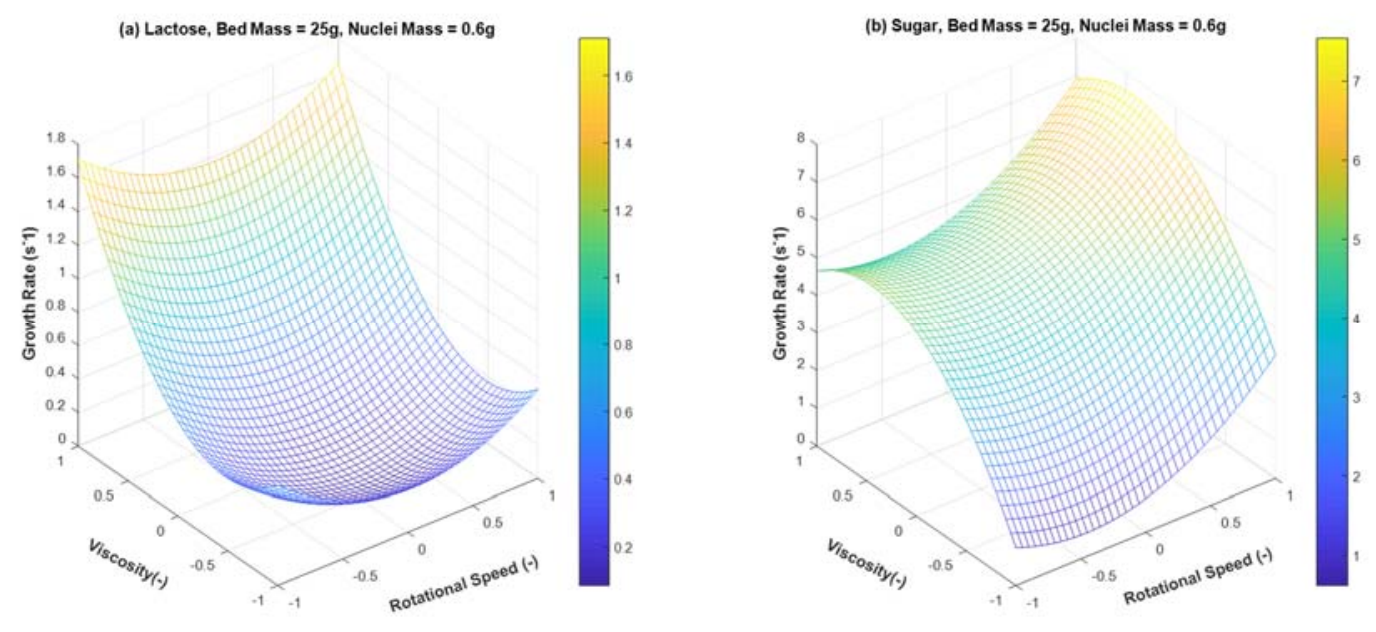

Figure 14: (a) Surface plots showing effect of binder viscosity and rotational speed of vessel on the nuclei growth rate

(a) Lactose (b) sugar. Plots were generated using Eq (8) and coefficient reported in Table 3 . Initial nuclei mass held constant at the minimum value $0.6 \mathrm{~g}(-1)$ and powder bed mass at $25 \mathrm{~g}(-1)$.

Table 4 summarizes the values of the variable coefficients that best fit an equation that calculates the maximum attainable nucleus mass. The results show that the factor that most affects the process differs for different powder being granulated. Sugar and tea, with a density of $705 \mathrm{~kg} / \mathrm{m}^{3}$ and $433 \mathrm{~kg} / \mathrm{m}^{3}$ respectively, are affected most by the speed of rotation of the mixer whereas lactose and starch, with densities of $1520 \mathrm{~kg} / \mathrm{m}^{3}$ and $1500 \mathrm{~kg} / \mathrm{m}^{3}$ respectively, are influenced by the nucleus's initial mass. On the other hand, Limestone, having the highest density $\left(2560 \mathrm{~kg} / \mathrm{m}^{3}\right)$ is most dependent of the binder's viscosity.

The goal behind this research paper was to find the conditions that maximize both rate of nuclei growth and the final granule mass. These correlations can help develop optimum solutions specific to each powder type as summarised in Table 6.

To further validate the obtained results, a simple calculation of a Stokes deformation number was performed. This number is a ratio of kinetic energy applied to the system to the energy required to cause a deformation in the granule. Tardos et al. proposed that the Stokes deformation number can be calculated using the following equation [7]:

$$
S t_{d e f}=\frac{\rho_{p} U^{2}}{2 \sigma_{d}}
$$

where $\boldsymbol{\rho}_{\boldsymbol{p}}$ the density of the nucleus is, $\sigma_{\boldsymbol{d}}$ is the dynamic strength of the nucleus and $U$ is the velocity of the nucleus.

The dynamic strength of the nucleus can be calculated from[5]: 


$$
\sigma_{d}=\frac{9}{8} \frac{(1-\varepsilon)^{2}}{\varepsilon^{2}} \frac{9 \pi \mu v_{p}}{16 d_{p}}
$$

where $\mu$ is the binder viscosity, $d_{p}$ surface-volume diameter of primary particles making up the nuclei, $\varepsilon$ is the porosity of the nucleus and $v_{p}$ is the velocity at which the particles move during the deformation. This is assumed to be $10 \%$ of the linear rotation speed of the vessel.

The literature states that if the values of Stokes deformation number are above 1, then the granule is expected to break apart [23]. After performing all necessary calculations, it was evident that, at the optimum conditions, the Stokes deformation number is always much less than 1 for all the studies powder type studied. This means that no breakage of the final granules is expected to occur. A plot of the growth rate with respect to the deformation number is depicted in Figure 15 (a).

Each value of growth rate shown in the figure is a representation of a powder type. It is observed that high growth rates are achieved at low deformation numbers and that in all the cases, no breakage will occur in the system. As can be seen in Figure 15 as the deformation numbers increase, there is a reduction in the growth rate of nuclei. Whilst high deformation number leads to slower growth of the nuclei, the final percentage gain in mass of the nuclei is higher at high deformation number (see Figure $15(b))$.

Table 5: Coefficients for the coded variables for increase in mass correlations

\begin{tabular}{|c|c|c|c|c|c|}
\hline Source Term & Lactose & Sugar & Tea & Limestone & Starch \\
\hline Intercept & 1.60 & 0.07 & 0.18 & 1.15 & 1.61 \\
\hline $\mathrm{A}$ & 0.10 & -0.17 & 0.10 & 0.19 & 0.26 \\
\hline $\mathrm{B}$ & 0.08 & -0.03 & -0.04 & 0.10 & 0.17 \\
\hline $\mathrm{C}$ & 0.31 & 0.07 & 0.06 & 0.75 & 0.98 \\
\hline $\mathrm{D}$ & -0.31 & 0.10 & 0.08 & 2.02 & -0.25 \\
\hline $\mathrm{A}^{2}$ & -0.11 & 0.10 & -0.06 & 0.22 & \\
\hline $\mathrm{B}^{2}$ & -0.03 & -0.07 & 0.01 & -0.20 & \\
\hline $\mathrm{C}^{2}$ & -0.55 & 0.00 & 0.03 & 0.48 & \\
\hline $\mathrm{D}^{2}$ & -0.20 & 0.02 & 0.00 & 1.88 & \\
\hline $\mathrm{A}^{3}$ & & 0.13 & -0.12 & & \\
\hline $\mathrm{B}^{3}$ & & 0.02 & 0.01 & & 0.95 \\
\hline $\mathrm{C}^{3}$ & & -0.04 & 0.03 & & \\
\hline $\mathrm{D}^{3}$ & & -0.15 & -0.09 & & 0.97 \\
\hline $\mathrm{R}^{2}$ value & 0.94 & 0.94 & 0.97 & & \\
\hline
\end{tabular}

Table 6: Optimum conditions for each powder type

\begin{tabular}{|c|c|c|c|c|c|c|c|}
\hline Powder & $\begin{array}{c}\text { Speed of } \\
\text { Rotation } \\
(\mathrm{rpm})\end{array}$ & $\begin{array}{c}\text { Mass of } \\
\text { Powder } \\
\text { Bed }(\mathrm{g})\end{array}$ & $\begin{array}{c}\text { Mass of } \\
\text { Initial } \\
\text { Nucleus } \\
(\mathrm{g})\end{array}$ & $\begin{array}{c}\text { Binder } \\
\text { Viscosity } \\
(\mathrm{mPa} . \mathrm{s})\end{array}$ & Rate $\left(\mathrm{s}^{-1}\right)$ & $\begin{array}{c}\text { Mass } \\
\text { Increase } \\
(\mathrm{g})\end{array}$ & $\begin{array}{c}\text { Mass } \\
\text { Increase } \\
(\%)\end{array}$ \\
\hline
\end{tabular}




\begin{tabular}{|c|c|c|c|c|c|c|c|}
\hline Lactose & 400 & 40.00 & 1.51 & 9740 & 1.37 & 1.41 & 93 \\
\hline Sugar & 170 & 27.72 & 1.47 & 8915 & 4.92 & 0.24 & 16 \\
\hline Tea & 380 & 25.97 & 1.95 & 7230 & 7.51 & 0.31 & 16 \\
\hline Limestone & 200 & 28.95 & 2.00 & 10400 & 0.66 & 4.74 & 237 \\
\hline Starch & 250 & 37.61 & 1.95 & 12000 & 0.59 & 2.34 & 120 \\
\hline
\end{tabular}

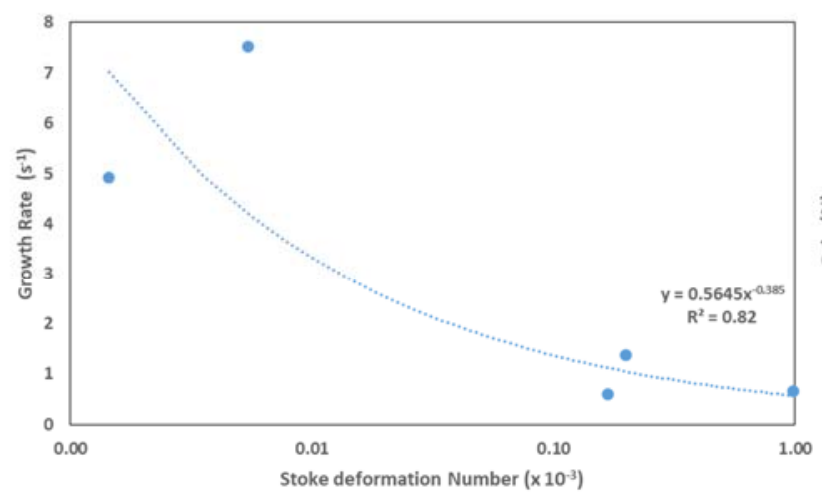

(a)

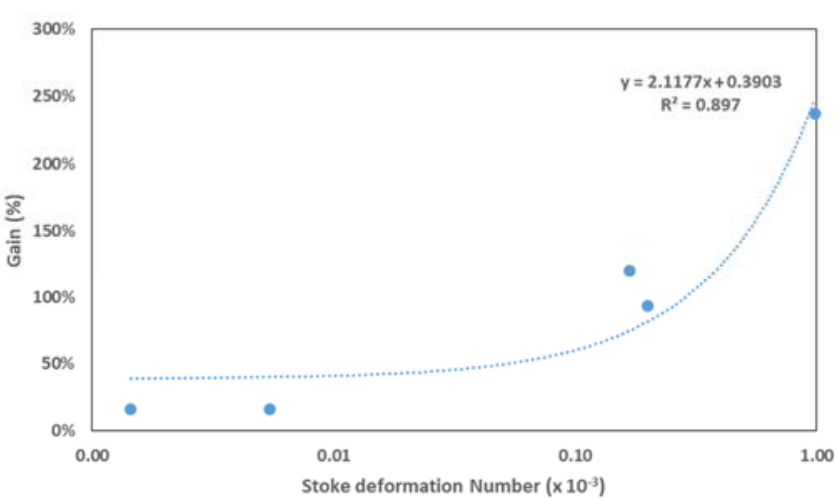

(b)

Figure 15: (a) variation of growth rate $\left(\mathrm{s}^{-1}\right)$ with Stokes deformation number (b) variation of percentage grain in mass with the Stokes deformation number.

\subsection{Effect of particle position on the powder bed}

While carrying out the experiments, it was noticed that the position of the initial granule in the powder bed played a role in the effectiveness of the granulation process. Therefore, an experiment was designed to test that hypothesis.

Five lactose granules with a mass of $0.6 \mathrm{~g}$ were prepared. The diameter of the used vessel was $100 \mathrm{~mm}$ and the mixer was set to rotate at $250 \mathrm{rpm}$ for $30 \mathrm{~s}$. This experiment was performed for the other granules at $10 \mathrm{~mm}, 20 \mathrm{~mm}, 30 \mathrm{~mm}$, and $40 \mathrm{~mm}$ from the centre of the vessel. Figure 16 shows the variation of the $\%$ gain in granule mass with respect to the position in the vessel, depicted as a ratio of the granule position to the diameter of the vessel $(100 \mathrm{~mm})$. 


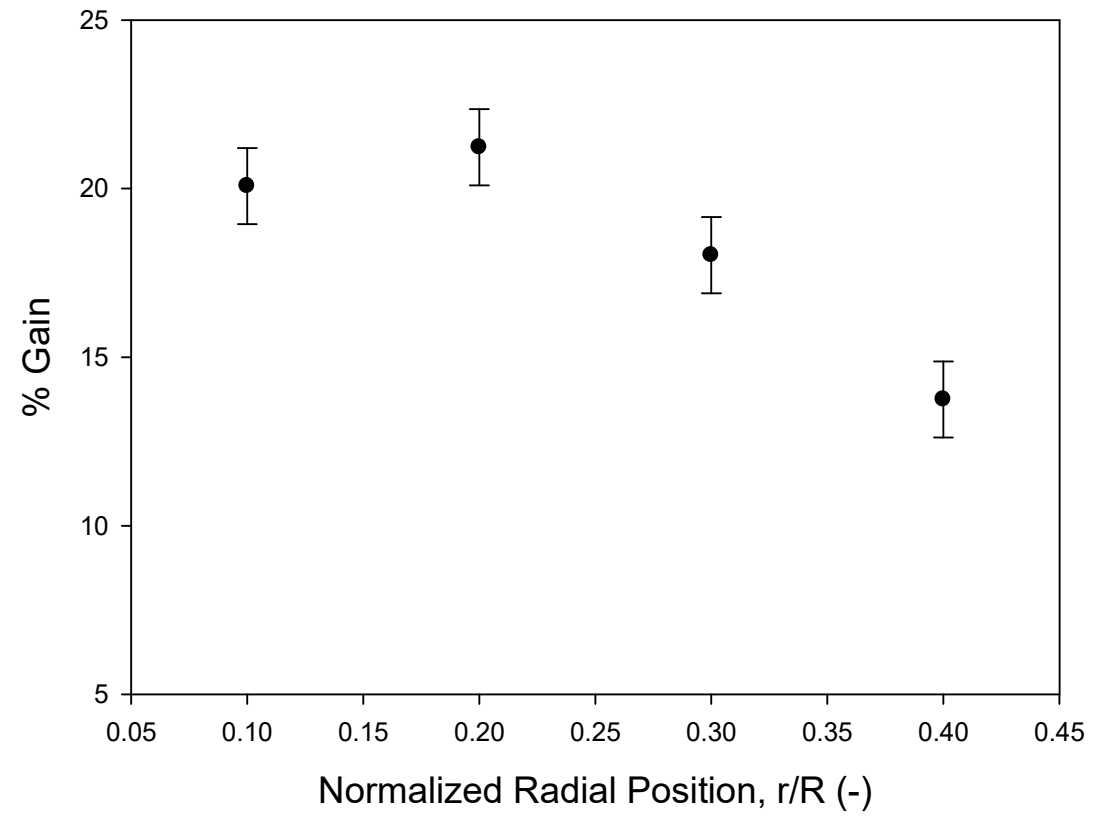

Figure 16: Variation of granule mass with respect to position on the powder bed. The results reported are an average of 5 repetitions.

As it is shown in Figure 16, the final mass of the granule decreases as the granule moves closer to the edge of the vessel.

When the nucleus starting position is farther away from the centre of the powder bed, the initial thrust, due to vessel rotation, caused the nucleus to roll on the powder bed until it reached the edge of the container and stayed in place. As the nuclei was closer to the edge, less rolling action took place which, in turn, decreased the efficiency of granulation. Due to its fixed position, penetration was the main reason for the increase in granule mass. When the granule was taken out for measurement, it was observed that a clump of powder was stuck to the bottom.

\section{CONCLUSION}

This research paper studies the process of nucleation and how it is affected by four process variables: speed of mixer rotation, powder bed mass, mass of the initial granule and binder viscosity on the wet granulation of five different powders. The powders under study were: lactose, tea, sugar, starch, and limestone. After a thorough analysis of the experimental results, it was concluded for sugar, starch, and limestone powders the rate of nuclei growth was mainly affected by the viscosity of the binder whereas for tea powder rotational speed of the vessel had the biggest influence. The binder viscosity had little effect on the growth rate of tea nuclei. It can be concluded that the initial position of the nuclei on the bed also has an influence on the growth rate of the nuclei which can be attributed to change in the contribution of the rolling action to the growth mechanism; contribution of nuclei rolling is less pronounced the closer the nuclei is to the wall. 


\section{REFERENCES}

[1] Z. Mirza, J. Liu, Y. Glocheux, A. B. Albadarin, G. M. Walker, and C. Mangwandi, "Effect of impeller design on homogeneity, size and strength of pharmaceutical granules produced by high-shear wet granulation," Particuology, vol. 23, pp. 31-39, 2015/12/01/ 2015.

[2] J. Litster and B. Ennis, The Science and Engineering of Granulation Processes: Springer Netherlands, 2013.

[3] T. Monteyne, J. Vancoillie, J.-P. Remon, C. Vervaet, and T. De Beer, "Continuous melt granulation: Influence of process and formulation parameters upon granule and tablet properties," European Journal of Pharmaceutics and Biopharmaceutics, vol. 107, pp. 249262, 2016/10/01/2016.

[4] M. Šantl, I. Ilić, F. Vrečer, and S. Baumgartner, "A compressibility and compactibility study of real tableting mixtures: The impact of wet and dry granulation versus a direct tableting mixture," International Journal of Pharmaceutics, vol. 414, pp. 131-139, 2011/07/29/ 2011.

[5] S. M. Iveson, J. D. Litster, K. Hapgood, and B. J. Ennis, "Nucleation, growth and breakage phenomena in agitated wet granulation processes: a review," Powder Technology, vol. 117, pp. 3-39, 2001/06/04/2001.

[6] J. D. Litster, "Scaleup of wet granulation processes: science not art," Powder Technology, vol. 130, pp. 35-40, 2003/02/19/ 2003.

[7] G. I. Tardos, M. I. Khan, and P. R. Mort, "Critical parameters and limiting conditions in binder granulation of fine powders," Powder Technology, vol. 94, pp. 245-258, 1997/12/15/ 1997.

[8] J. D. Osborne, R. P. J. Sochon, J. J. Cartwright, D. G. Doughty, M. J. Hounslow, and A. D. Salman, "Binder addition methods and binder distribution in high shear and fluidised bed granulation," Chemical Engineering Research and Design, vol. 89, pp. 553-559, 2011/05/01/2011.

[9] S. M. Iveson, J. D. Litster, and B. J. Ennis, "Fundamental studies of granule consolidation Part 1: Effects of binder content and binder viscosity," Powder Technology, vol. 88, pp. 1520, 1996/07/01/ 1996.

[10] M. Börner, M. Michaelis, E. Siegmann, C. Radeke, and U. Schmidt, "Impact of impeller design on high-shear wet granulation," Powder Technology, vol. 295, pp. 261-271, 2016/07/01/ 2016.

[11] C. Mangwandi, M. J. Adams, M. J. Hounslow, and A. D. Salman, "An investigation of the influence of process and formulation variables on mechanical properties of high shear granules using design of experiment," International Journal of Pharmaceutics, vol. 427, pp. 328-336, 2012/05/10/ 2012.

[12] C. Mangwandi, A. B. Albadarin, A. a. H. Al-Muhtaseb, S. J. Allen, and G. M. Walker, "Optimisation of high shear granulation of multicomponent fertiliser using response surface methodology," Powder Technology, vol. 238, pp. 142-150, 2013/04/01/ 2013.

[13] N. Rahmanian, A. Naji, and M. Ghadiri, "Effects of process parameters on granules properties produced in a high shear granulator," Chemical Engineering Research and Design, vol. 89, pp. 512-518, 2011/05/01/ 2011.

[14] Y. S. Cheong, C. Mangwandi, J. Fu, M. J. Adams, M. J. Hounslow, and A. D. Salman, "Chapter 26 A Mechanistic Description of Granule Deformation and Breakage," Handbook of Powder Technology, vol. 12, pp. 1055-1120, 2007/01/01/ 2007.

[15] Hapman. (2017). Bulk Material Density Guide. Available: http://www.hapman.com/resources/bulk-material-density-guide

[16] C. Mangwandi, S. N. A. Suhaimi, J. T. Liu, R. M. Dhenge, and A. B. Albadarin, "Design, production and characterisation of granular adsorbent material for arsenic removal from contaminated wastewater," Chemical Engineering Research and Design, vol. 110, pp. 7081, 2016/06/01/ 2016. 
[17] T. Zhang, "Analysis of particle flow in rotating vessel and high shear mixing devices using High Speed Video Imaging and Discrete Element Method simulation (DEM)" " MPhil in Chemical Engineering MPhil, Chemistry \& Chemical Engineering, Queen's University Belfasr, Belfast, United Kingdom, 2016.

[18] A. M. Bouwman, M. R. Visser, G. M. H. Meesters, and H. W. Frijlink, "The use of Stokes deformation number as a predictive tool for material exchange behaviour of granules in the 'equilibrium phase' in high shear granulation," International Journal of Pharmaceutics, vol. 318, pp. 78-85, 2006/08/02/ 2006.

[19] W.-D. Tu, A. Ingram, J. Seville, and S.-S. Hsiau, "Exploring the regime map for high-shear mixer granulation," Chemical Engineering Journal, vol. 145, pp. 505-513, 2009/01/01/ 2009.

[20] F. Hoornaert, P. A. L. Wauters, G. M. H. Meesters, S. E. Pratsinis, and B. Scarlett, "Agglomeration behaviour of powders in a Lödige mixer granulator," Powder Technology, vol. 96, pp. 116-128, 1998/05/01/ 1998.

[21] J. Litster and B. Ennis, "Wetting, Nucleation and Binder Distribution," in The Science and Engineering of Granulation Processes, J. Litster and B. Ennis, Eds., ed Dordrecht: Springer Netherlands, 2004, pp. 37-74.

[22] M. Cavinato, E. Franceschinis, S. Cavallari, N. Realdon, and A. Santomaso, "Relationship between particle shape and some process variables in high shear wet granulation using binders of different viscosity," Chemical Engineering Journal, vol. 164, pp. 292-298, 2010/11/01/ 2010.

[23] S. M. Iveson, P. A. L. Wauters, S. Forrest, J. D. Litster, G. M. H. Meesters, and B. Scarlett, "Growth regime map for liquid-bound granules: further development and experimental validation," Powder Technology, vol. 117, pp. 83-97, 2001/06/04/ 2001. 